\title{
A ORGANIZAÇÃO DOS TRABALHADORES NO LOCAL DE TRABALHO: ANÁLISE DA DISCIPLINA JURÍDICA NO BRASIL E NA ITÁLIA
}

\section{L'ORGANIZZAZIONE DEI LAVORATORI SUL LUOGO DI LAVORO: ANALISI DELLA DISCIPLINA LEGALE IN BRASILE E IN ITALIA}

\section{Anna Carolina de Oliveira Azevedo ${ }^{1}$}

Resumo: A organização dos trabalhadores no local de trabalho é fruto de conquistas históricas da classe trabalhadora, bem como da evolução do conceito de liberdade sindical. O espaço da empresa engloba uma diversidade de relações intersubjetivas, sendo, ainda, onde emergem, intensamente, as contradições e conflitos entre capital e trabalho. O presente artigo objetiva analisar a disciplina jurídica da organização dos trabalhadores no local de trabalho (OLT), no Brasil e na Itália. Busca-se examinar as principais normas internacionais que tratam do tema, cotejando-as com as disposições legais e com algumas estruturas de representação interna existentes nos mencionados países. Verifica-se que a Itália possui uma experiência consolidada de organização no local de trabalho e uma legislação básica adequada às diretrizes da Organização Internacional do Trabalho. No caso brasileiro, identificam-se importantes experiências de OLT, em especial como consequência do denominado "novo sindicalismo”. Não há, entretanto, um regramento nacional amplo para as representações internas, tampouco a definição de garantias e prerrogativas aos representantes, o que depende de negociação coletiva. Em que pesem os avanços práticos e institucionais verificados, em ambas as realidades, a representação dos trabalhadores nos locais de trabalho ainda se apresenta como desafio para o conjunto dos trabalhadores e para o movimento sindical.

\section{Palavras-chave: ORGANIZAÇÃO NO LOCAL DE TRABALHO. REPRESENTAÇÃO INTERNA. LIBERDADE SINDICAL.}

\begin{abstract}
The organization of workers in the workplace is the result of historical achievements of the working class, as well as the evolution of the concept of freedom of association. The company's space includes a diversity of interpersonal relationships, which is also where they emerge, intensely, the contradictions and conflicts between capital and labor.
\end{abstract}

1 Especialista em Direito do Trabalho Ítalo-brasileiro pela Universidade Federal de Minas Gerais e Università degli studi di Roma Tor Vergata. Auditoria Interna da Controladoria-Geral do Estado de Minas Gerais (CGE MG). 
This article aims to analyze the legal framework of the organization of workers at work (OLT), in Brazil and in Italy. The goal is to examine the main international standards, dealing with the theme from their correspondence with the legal provisions and with the internal representation of some structures existing in the countries listed. Italy has a long experience of organizing in the workplace and appropriate legislation to the guidelines of the International Labour. In the Brazilian case, identify important experiences OLT, in particular as a result of the so-called "new unionism". There is, however, national rules for the internal representations, the definition of guarantees and privileges to the representatives, that depends on collective bargaining. Despite the progress registered in institutional and practical both realities, the representation of employees in the workplace still looks like a challenge for all workers and the trade union movement.

Keywords: ORGANIZATION IN THE WORKPLACE . INTERNAL REPRESENTATION . FREEDOM OF AUDITORS. 


\section{INTRODUÇÃO}

Muitas foram as análises produzidas, nos últimos anos, que apontam para a obsolência da organização sindical clássica diante da estrutura sócio-produtiva surgida com o pós-fordismo.

De fato, os sindicatos estão no centro das transformações políticas e jurídicas em curso. Todavia, a chamada “crise do sindicalismo" deve ser compreendida de forma mais ampla, como um dos reflexos da crise do movimento de trabalhadores em geral. Nas palavras de Ricardo Antunes trata-se de uma crise constituída por elementos de grande complexidade, que afeta "tanto a materialidade da classe trabalhadora, a sua forma de ser, quanto a sua esfera mais propriamente subjetiva, política, ideológica, dos valores e do ideário que pautam suas ações e práticas concretas” (2009, p. 186).

Desde a década de 1970, o mundo vivencia um quadro de crise estrutural do sistema capitalista (MÉSZÁROS, 2009), marcada, dentre outras características, pela implementação de um vastíssimo processo de reestruturação produtiva como forma de recuperação do ciclo de reprodução do capital (ANTUNES, 2009, p. 186). Tal fato, aliado ao fim da experiência socialista da União Soviética (URSS) e à emergência da agenda neoliberal, trouxe grandes efeitos para o mundo do trabalho e para o movimento sindical.

Ao movimento sindical brasileiro, caracterizado por uma estrutura restritiva forjada há mais de setenta anos, bem como à organização mais ampla dos trabalhadores, estão colocados desafios de alta complexidade, dentre os quais se destaca a organização no local de trabalho.

O local de trabalho adquire centralidade quando se pensa a organização dos trabalhadores e a atuação dos sindicatos. Trata-se do marco espacial no qual o trabalhador exerce suas funções, cria relações e passa grande parte do seu dia. É no local de trabalho, também, que emergem as contradições e conflitos entre capital e trabalho, ligados às condições de trabalho, reivindicações salariais, doenças ocupacionais, acidentes de trabalho, assédio moral, conflitos com chefias e gerentes, entre outros.

Dessa forma, o local de trabalho apresenta-se como espaço prioritário da atuação sindical. E, justamente por esse motivo, a organização no âmbito da empresa constitui ponto de tensão nas relações entre trabalhadores e empregadores.

Foi na Europa do século XIX que surgiram as primeiras manifestações do que hoje se denomina organização no local de trabalho (MEIRELLES, 2008, p. 123). 
No Brasil, a possibilidade desse tipo de organização é ainda restrita, sendo comum na doutrina a menção à arbitrariedade quanto ao espaço da fábrica, por muito tempo entendido como “território reservado do empregador”, para utilizar a expressão de José Francisco Siqueira Neto (2001, p. 102). Essa característica marcante das relações de trabalho no país dificulta que o trabalhador tenha direito de organização interna.

Nesse sentido, Cássio Casagrande aponta que dentre os pontos de tensão da proposta de reforma sindical apresentada pelo governo brasileiro, está a representação no local de trabalho, veementemente criticada pelo empresariado nacional (2012).

Os diversos estudos sobre a montagem da estrutura sindical e de relações de trabalho indicam a influência exercida, em nosso país, pelo sindicalismo e pela disciplina justrabalhista construídos em solo italiano, razão pela qual se recorre, também quanto à organização no local de trabalho, ao estudo comparado entre o ordenamento jurídico pátrio e o ordenamento italiano.

Atualmente, Brasil e Itália vivenciam conjunturas socioeconômicas, em certa medida, diferentes. No Brasil, em que pese a ofensiva neoliberal sobre os direitos trabalhistas operada a partir da década de 1990, assiste-se a uma recente redução dos níveis de desemprego, fato que coloca os trabalhadores em melhores condições para negociar os contratos de trabalho, inclusive com tentativas de ampliar as pautas das negociações e as garantias institucionalizadas.

A Itália, por sua vez, sente intensamente os efeitos da crise econômica em curso, ocasionando perda de direitos e disseminação das formas precárias de trabalho.

Em ambas as conjunturas, porém, a atuação coletiva dos trabalhadores mostra-se decisiva, trazendo para o centro do debate o papel que pode ser desempenhado pela organização articulada nas bases, ou seja, nos locais de trabalho.

Entende-se que a consolidação do direito à organização no local de trabalho segue como um grande desafio para os trabalhadores brasileiros e a análise das experiências e do tratamento normativo da questão na Itália pode implicar em importantes contribuições para a democratização das relações de trabalho no Brasil.

\section{LIBERDADE SINDICAL E A ORGANIZAÇÃO DOS TRABALHADORES NO LOCAL DE TRABALHO}


A liberdade sindical constitui direito humano fundamental, decorrente do reconhecimento do direito de associação.

Sob a ótica dos trabalhadores, é um conjunto de direitos e liberdades individuais de cada trabalhador, e um complexo de direitos e liberdades coletivas atribuídos às organizações sindicais propriamente ditas (SIQUEIRA NETO, 2001, p. 85).

A definição da liberdade sindical ocorre nos moldes consagrados pela Declaração Universal dos Direitos do Homem da Organização das Nações Unidas (ONU), de 1948, e pelos Pactos Internacionais dela decorrentes - sobre os Direitos Econômicos, Sociais e Culturais e sobre os Direitos Civis e Políticos, ambos de 1966 - bem como pelos instrumentos da Organização Internacional do Trabalho (OIT).

Ao longo do tempo, em especial após a Segunda Guerra Mundial, a liberdade sindical deixou de ser entendida apenas como um direito subjetivo de associação, para abranger, também, a limitação ao poder do Estado e do empregador de desnaturar ou obstaculizar o exercício desse direito, bem como o direito à livre organização e ação dos sindicatos (SILVA, 2011).

A liberdade sindical constitui-se como princípio fundamental do Direito Sindical e ponto de conexão e articulação entre os diversos institutos do Direito do Trabalho, vez que assume uma função preliminar de condição para a atuação dos direitos individuais e coletivos (SIQUEIRA NETO, 2001, p. 82).

Gino Giugni citado por José Cláudio M. de Brito Filho, ao se referir à liberdade sindical como princípio contido na Constituição da Itália, afirma que ela deve ser vista sob dois prismas: como liberdade perante o Estado e do ponto de vista das relações interprivadas (2012, p. 72).

Em abrangente síntese, José Francisco Siqueira Neto aduz tratar-se a liberdade sindical:

\footnotetext{
Do amplo direito, em relação ao Estado e às contrapartes, de constituição de organizações sindicais em sentido teleológico (comissões, delegados...), em todos os níveis e âmbitos territoriais, de filiação e não filiação sindical, de militância e ação, inclusive nos locais de trabalho, gerador de autonomia coletiva, preservado mediante a sua garantia contra todo e qualquer ato voltado a impedir ou a obstaculizar o exercício dos direitos a ele inerentes, ou de outros a ele conexos, instituto nuclear do direito do trabalho, instrumentalizador da efetiva atuação e participação democrática dos atores sociais nas relações de trabalho, em todas as suas esferas, econômicas, sociais, administrativas e públicas (SIQUEIRA NETO, 2001, p. 86).
}

Destaque para o conceito de "sindicato em sentido teleológico" esposado por José Francisco Siqueira Neto, a partir do qual se pode afirmar que a liberdade sindical e de9 
organização deve abranger todas as estruturas de organização de trabalhadores que visem à garantia de direitos e melhoria das condições de trabalho, sejam internas ou externas, subsumidas ou não ao conceito legal de sindicato.

Vê-se, assim, que a liberdade de organização no local de trabalho é uma das facetas de realização da liberdade sindical, destinada a equilibrar a desigual distribuição de poder nas relações de trabalho. Trata-se de instrumento de contrapoder dos empregados em face dos empregadores (SIQUEIRA NETO, 2001, p. 86), vez que estes, pela própria estrutura do capitalismo, já se apresentam como um poder estabelecido.

\footnotetext{
A legitimação das liberdades sindicais nos locais de trabalho, portanto, marca uma etapa fundamental do processo histórico que deságua no reconhecimento específico dos direitos sindicais, destinados a assegurar a efetividade da representação e da autoproteção coletiva, no local onde tem raízes a experiência concreta das relações de trabalho (SIQUEIRA NETO, 2001, p. 91).
}

Por organização no local de trabalho (OLT) compreende-se o conjunto de ações e organismos que têm por finalidade a defesa de interesses e direitos dos trabalhadores no espaço da empresa, o que inclui a representação dos trabalhadores e as prerrogativas de atuação direta da coletividade de trabalhadores de determinado local de trabalho (por exemplo, a realização de assembleias no interior das empresas).

Verifica-se que a expressão OLT é mais comum nos estudos de viés político e/ou sociológico, enquanto Representação no Local de Trabalho (RLT) é a expressão mais utilizada pela doutrina jurídica.

Para os objetivos deste artigo, entende-se que as duas expressões podem ser utilizadas para nomear os institutos em estudo, havendo uma relação de equivalência entre elas.

\section{A REPRESENTAÇÃO DOS TRABALHADORES}

O sindicato é o representante dos trabalhadores por excelência, coordenando e defendendo os interesses de determinado grupo. Nos termos do artigo $8^{\circ}$, inciso III, da Constituição da República, ao ente sindical cabe a defesa dos direitos e interesses coletivos ou individuais da categoria, inclusive em questões judiciais ou administrativas.

Observa-se, então, que a Carta Magna atribui grande legitimidade à atuação dos sindicatos, certamente em razão da influência das lutas sindicais e políticas do período constituinte e sua conexão com o estabelecimento dos direitos ligados ao trabalho. 
Ocorre que a representação dos trabalhadores pode tomar diversas formas - legal ou voluntária; individual ou coletiva - e abranger distintos âmbitos - toda a categoria, apenas os associados ou os trabalhadores de determinada empresa (BRITO FILHO, 2012, p. 300).

Sob a ótica do Direito Civil, representação é a capacidade atribuída a alguém para praticar atos ou administrar interesses em nome de outrem (BARROS, 1998, p. 179).

Segundo Amauri Mascaro do Nascimento, "representante é aquele que atua em nome de outrem, para quem age, defendendo os seus interesses” (2005, p. 188). Poder-se-ia acrescentar que, na esfera sindical, não se trata da defesa de interesses alheios, mas, antes, da defesa de interesses coletivos, consolidados a partir da manifestação da maioria da categoria ou dos representados, mediante os canais legitimamente instituídos.

A expressão “representação dos trabalhadores” é utilizada neste trabalho nos termos trazidos pelo artigo $3^{\circ}$, da Convenção $\mathrm{n}^{\circ}$ 135, da OIT que, a despeito de referir-se especificamente à representação no local de trabalho, entende-se passível de aplicação para a representação dos trabalhadores em geral.

Prescreve o artigo $3^{\circ}$ :

Para os fins da presente Convenção, os termos "representantes dos trabalhadores” designam pessoas reconhecidas como tais pela legislação ou a prática nacionais, quer sejam:

a) representantes sindicais, a saber representantes nomeados ou eleitos por sindicatos ou pelos membros de sindicatos;

b) ou representantes eleitos, a saber representantes livremente eleitos pelos trabalhadores da empresa, conforme as disposições da legislação nacional ou de convenções coletivas, e cujas funções não se estendam a atividades que sejam reconhecidas, nos países interessados, como dependendo das prerrogativas exclusivas dos sindicatos (ORGANIZAÇÃO INTERNACIONAL DO TRABALHO, 1971a).

A partir da definição mencionada, é possível afirmar que a OIT admite duplo canal de representação laboral: pelo sindicato e por organismos não sindicais (BRITO FILHO, 2012, p. 303). Essa forma é a adotada pela maior parte dos países (KAUFMANN, 2005, p. 389), incluídos Brasil e Itália.

Sobre as diferenças que guardam os dois tipos de representação, José Cláudio M. de Brito Filho assevera:

1) os representantes sindicais têm vinculação direta com uma entidade sindical, podendo ou não ter sido escolhidos, diretamente, pelos trabalhadores e, os não sindicais, por sua vez, têm esta vinculação direta estabelecida com os próprios trabalhadores, muito embora possam manter vínculo com uma entidade sindical e 2) a atuação dos representantes sindicais é exercida tanto dentro como além dos limites da empresa, enquanto a dos representantes não sindicais é, via de regra, exercida nos limites da empresa (2012, p. 304). 
A doutrina aponta, ainda, que na representação sindical prepondera o caráter associativo, sendo relevante a condição do trabalhador de sindicalizado ou não; já a representação não sindical abrange todos os trabalhadores de um determinado ambiente de trabalho (KAUFMANN, 2005, p. 386).

Tal diferenciação é facilmente verificada nos sistemas que adotam a pluralidade sindical - como ocorre na Itália - nos quais, em uma mesma empresa, há a atuação e a representação de diferentes sindicatos. No caso da estrutura sindical brasileira, porém, deve ser relativizada, já que o sindicato, muitas vezes, atua não apenas em benefício de seus associados, mas como representante de toda a categoria. Uma negociação coletiva realizada por determinado sindicato, por exemplo, gera efeitos na esfera jurídica e nas relações de trabalho de toda a categoria, não apenas dos sindicalizados.

\subsection{Representação no local de trabalho}

A representação dos trabalhadores no local de trabalho (RLT) é entendida como o “conjunto de meios destinados à discussão e manifestação dos empregados no local de trabalho, tendo em vista o desenvolvimento de entendimentos com o empregador destinados à efetivação ou à reivindicação de direitos e deveres” (NASCIMENTO apud BRITO FILHO, 2012, P. 317). É um instrumento criado pelos trabalhadores visando à democratização das relações de trabalho dentro da empresa e ao atendimento imediato dos problemas surgidos naquele âmbito (RAGHI; MARRAS, 2008, p. 54).

Assim como a representação dos trabalhadores em geral, a que se efetiva no local de trabalho pode comportar dois modelos: a) o dual, dualista ou misto, quando a representação é exercida por representantes sindicais e por organismo unitário ou não sindical; e b) o singular, no qual ou existe a representação sindical ou a representação por organismo unitário (BRITO FILHO, 2012, p. 317; KAUFMANN, 2005, p. 395; BARROS, 1998, p. 179).

Os ordenamentos jurídicos brasileiro e italiano adotam o primeiro modelo, segundo será apresentado adiante.

Para José Augusto Rodrigues Pinto citado por Marcus Kaufmann, a representação sindical nos locais de trabalho destina-se ao acompanhamento e à fiscalização das relações da categoria com a empresa, bem como à atividade amplamente reivindicativa de melhores condições de trabalho. Já a representação “de empregados”, de perfil unitário e extrasindical, 
destina-se à atividade reivindicativa estrita aos seus interesses internos na empresa (2005, p. 368).

O principal documento internacional que trata da matéria é a Convenção $n^{\circ} 135$, da $\mathrm{OIT}^{1}$. A convenção prescreve garantias e facilidades a serem conferidas aos representantes dos trabalhadores, sejam eles vinculados a sindicato ou eleitos diretamente pelo pessoal da empresa.

Conforme Marcus Kaufmann, a representação sindical já encontrava tutela na Convenção $\mathrm{n}^{0}$ 98, da OIT; a inovação é que a Convenção $\mathrm{n}^{0} 135$ disciplina mais adequadamente a representação exercida nos locais de trabalho, direcionada, sobretudo, aos delegados sindicais (2005, p. 373).

A representação no local de trabalho encontra sua definição no artigo $3^{\circ}$ da Convenção $n^{\circ} 135$, da OIT, reproduzido anteriormente.

Importante salientar a ressalva contida na parte final desse dispositivo (alínea b), no sentido de que a representação exercida por trabalhadores eleitos, ou seja, a do tipo unitária e extrasindical, não deve desempenhar atividades atribuídas aos sindicatos de forma exclusiva, nos termos da legislação nacional. Esse entendimento foi reproduzido também no artigo $5^{\circ}$ da citada Convenção, o que demonstra a preocupação da OIT de que o reconhecimento da pluralidade de representação dos trabalhadores não crie situações de disputa entre os organismos, o que apenas enfraqueceria a organização coletiva e a defesa dos interesses dos trabalhadores:

Art. $5^{\circ}$. Quando uma empresa contar ao mesmo tempo com representantes sindicais
e representantes eleitos, medidas adequadas deverão ser tomadas, cada vez que for
necessário, para garantir que a presença de representantes eleitos não venha a ser
utilizada para o enfraquecimento da situação dos sindicatos interessados ou de seus
representantes e para incentivar a cooperação, relativa a todas as questões
pertinentes, entre os representantes eleitos, por uma Parte, e os sindicatos
interessados e seus representantes, por outra Parte (ORGANIZAÇÃO
INTERNACIONAL DO TRABALHO, 1971a).

As representações sindical e não sindical constituem organismos autônomos, mas que podem - e devem - buscar uma atuação complementar e colaborativa.

Nos dizeres de Marcus Kaufmann:

Nenhuma fórmula de participação dos trabalhadores pode funcionar e dar resultados positivos se é prejudicial ao sindicalismo, se tratar de eliminá-lo, se provoca a

\footnotetext{
${ }^{1}$ No Brasil, a Convenção $n^{0} 135$, da OIT foi aprovada pelo Decreto Legislativo $\mathrm{n}^{0}$ 86, de 14 de dezembro de 1989, ratificada em 18 de maio de 1990 e promulgada pelo Decreto $\mathrm{n}^{0}$ 131, de 22 de maio de 19وß (NASCIMENTO, 2005, p. 536). Na Itália, a Convenção também foi ratificada.
} 
desconfiança ou a oposição ou infringe, de alguma forma, o princípio da liberdade sindical (2005, p. 394).

Na prática, conforme observa Giancarlo Perone, há uma inegável vocação dos sindicatos para influenciar os organismos internos de representação dos trabalhadores (apud SIQUEIRA NETO, 2001, p. 92).

Ao prever mecanismos de proteção dos representantes, a Convenção no 135 traz a diretiva do combate às práticas que afrontam o exercício da representação, tal qual a Convenção nº 98 fez com as práticas antissindicais (KAUFMANN, 2005).

Os preceitos da Convenção no 135 são complementados pela Recomendação n ${ }^{0}$ 143, da OIT, que propõe algumas formas de proteção aos representantes internos dos trabalhadores, dentre as quais se destaca aquelas previstas no item 2 , do $\S 6^{\circ}$ da Recomendação, a saber:

a) a definição precisa e detalhada das razões que justifiquem o fim de emprego de representantes de trabalhadores;

b) a exigência de consulta a um órgão independente, público ou privado, ou misto, ou de seu parecer ou anuência, antes de se concretizar a demissão de representante de trabalhadores;

c) um procedimento especial de recurso acessível a representantes de trabalhadores que considerem injustificável o fim de seu emprego, ou que tenham sido vítimas de uma mudança desfavorável em suas condições de emprego ou de tratamento injusto; d) com relação ao fim de emprego, sem justa causa, de representantes de trabalhadores, disposição de correção que inclua, a menos que contrarie os princípios básicos da lei do país em causa, a reintegração desses representantes em seu emprego, com pagamento de salários não-pagos e com a manutenção de seus direitos adquiridos;

e) disposição que imponha ao empregador, no caso de qualquer demissão alegada como discriminatória ou de mudança desfavorável das condições de emprego de representantes de trabalhadores, o ônus de provar a correção dessa medida;

f) o reconhecimento da prioridade a ser dada a representantes de trabalhadores com relação à sua manutenção no emprego no caso de redução da mão-de-obra (ORGANIZAÇÃO INTERNACIONAL DO TRABALHO, 1971b).

A Recomendação vai além na proteção aos representantes, estendendo-a, também, aos candidatos ou indicados nos processos de escolha (item $1, \S 7^{\circ}$ ), bem como aos representantes que tiveram seus mandatos concluídos (item $2, \S 7^{\circ}$ ), pelo prazo fixado na legislação pátria ou acordado em instrumentos coletivos (MEIRELLES, 2008, p. 126).

Por fim, cabe mencionar a quarta parte da Recomendação, em especial os $\S \S 10$ a 17, que tratam das principais formas sugeridas para a efetivação das facilidades a serem concedidas aos representantes para o exercício de suas funções, dentre as quais destaca Marcus Kaufmann: 
(i) o desfrute, sem prejuízo do salário, encargos sociais ou outras vantagens, do tempo livre necessário, que poderia ser limitado razoavelmente de modo a não prejudicar o bom funcionamento da empresa ( $§ 10$, itens 1 e 3 ) e que poderia ser usufruído mediante uma licença concedida pelo supervisor imediato ou de outro competente representante da direção, nomeado para tal mister, antes de se fazer uso do tempo livre durante as horas de trabalho, que não poderia ser negado a não ser por um justo motivo ( $§ 10$, item 2);

(ii) o desfrute do tempo livre necessário para assistir a reuniões, cursos de formação, seminários, congressos e conferências sindicais ( $§ 11$, item 1), sem prejuízo do salário, encargos sociais ou outras vantagens, sendo que a questão de determinar a quem corresponderiam os ônus resultantes da concessão desse tempo poderia ser tratada pela legislação nacional, pelos convênios coletivos de trabalho, por laudos arbitrais ou por decisões judiciais (§ 11, item 2);

(iii) a autorização para que os representantes entrem, quando necessário, em todos os locais de trabalho na empresa, para lhes permitir o desempenho de suas funções de representação (§ 12);

(iv) a possibilidade de os representantes entrarem em comunicação, sem dilação indevida, com a direção da empresa e com seus representantes autorizados a tomar decisões (§ 13);

(v) a permissão para que os representantes fossem autorizados, se vinculados a entidades sindicais, a cobrar periodicamente as cotas sindicais nos locais de trabalho (§ 14);

(vi) a autorização para que representantes que atuassem em nome de um sindicato fossem autorizados a afixar avisos sindicais nos locais da empresa, em lugar ou lugares estabelecidos de acordo com a direção, de fácil acesso (§ 15, item 1); e a distribuir boletins, folhetos, publicações e outros documentos do sindicato entre os trabalhadores da empresa ( $\S 15$, item 2 ), desde que tais papéis tenham relação com as atividades sindicais normais e sua afixação e distribuição não prejudiquem o funcionamento normal da empresa e nem o bom aspecto ambiental (§ 15, item 3); facilidades que também devem ser estendidas aos representantes eleitos, unitários, por razões elementares, para a prática de suas funções (§ 15, item 4);

(vii) o acesso, disponibilizado pela empresa, às facilidades materiais e as informações necessárias ao exercício das funções, nas condições e na medida que pudessem ser determinadas pela legislação, pelos convênios coletivos de trabalho, por laudos arbitrais ou por decisões judiciais (§ 16); e

(viii) a autorização para que representantes sindicais que não trabalhassem na empresa, mas cujo sindicato tivesse filiados nela empregados, adentrassem a empresa ( $\S 17$, item 1), segundo os métodos estabelecidos pela legislação nacional, pelos convênios coletivos de trabalho, pelos laudos arbitrais ou por decisões judiciais (§ 17, item 2) (2005, p. 379-380).

\section{Conforme exposto, ditas facilidades podem ser determinadas pela legislação}

nacional, pelos convênios coletivos de trabalho, por laudos arbitrais ou por decisões judiciais.

No Brasil, na falta de disposições legislativas de caráter geral, tais prerrogativas são instituídas por outras vias, especialmente mediante cláusulas em negociações coletivas.

De forma exemplificativa, têm-se as seguintes cláusulas do Acordo Coletivo firmado entre o Sindicato dos Empregados de Tecnologias da Informação nos Estados do Amapá e do Pará e a empresa Processamento de Dados do Estado do Pará (PRODEPA), com vigência de 01/06/2010 a 31/05/2012:

Cláusula $n^{\circ} 045$ - ORGANIZAÇÃO POR LOCAL DE TRABALHO

Será reconhecida uma Organização por Local de Trabalho - OLT eleita para um mandato de até 2 anos, prorrogável em circunstâncias emergenciais, pelo período 15 máximo de 2 meses, hipótese em que os titulares encaminharão à Empresa cópia 
da ata por intermédio da qual a assembléia dos trabalhadores tenha deliberado nesse sentido.

$\S 1^{\circ}$ - A OLT terá por finalidade defender os interesses dos trabalhadores, sendo permitida a reeleição de seus componentes por apenas um mandato subseqüente.

$\S 2^{\circ}$ - No caso de promulgação de lei que venha a regulamentar ou constituir entidade assemelhada, as partes reunir-se-ão para acordar a adequação desse instrumento, de forma a não duplicar representações.

$\S 3^{\circ}$ - As eleições dos membros das OLTs serão coordenadas pelo SINDPD-AP/PA e acompanhadas pela PRODEPA.

$\S 4^{\circ}$ - Os representantes e respectivos suplentes serão eleitos por todos os empregados da PRODEPA, através de voto direto e secreto.

$\S 5^{\circ}$ - Os membros titulares das OLTs disporão de até 2 horas semanais de suas respectivas jornadas de trabalho para reuniões, previamente negociadas com as respectivas chefias imediatas em local disponibilizado pela PRODEPA, previamente solicitado.

$\S 6^{\circ}$ - A disponibilidade de tempo prevista no $\S$ anterior não se aplica aos empregados suplentes das OLTs, salvo em caso de substituição do representante titular, previamente formalizada junto as respectivas chefias imediatas.

Cláusula $n^{\circ} 046$ - COMPOSIÇÃO DAS ORGANIZAÇÕES POR LOCAL DE TRABALHO

A Composição da OLT será estabelecida de acordo com o quantitativo de empregados:

I - até 500 empregados - 4 representantes

II - 501 a 600 empregados - 5 representantes

III - 601 a 700 empregados - 6 representantes

$\S$ Único: É vedada a eleição de empregados contratados para exercerem exclusivamente cargos de confiança.

Cláusula $n^{\circ} 025$ - GARANTIA DE EMPREGO PARA MEMBROS DAS OLTS

Será assegurada a garantia de emprego aos membros titulares e suplentes das OLTs, desde o registro da candidatura e, se eleitos, até 1 ano após o final do mandato, salvo se cometerem falta grave nos termos da Lei.

(SINDICATO DOS EMPREGADOS DE TECNOLOGIAS DA INFORMAÇÃO NOS ESTADOS DO AMAPÁ E DO PARÁ; PROCESSAMENTO DE DADOS DO ESTADO DO PARÁ, 2012).

\section{FORMAS DE REPRESENTAÇÃO DOS TRABALHADORES NO LOCAL DE TRABALHO NO BRASIL}

Conforme afirma Kaufmann (2005, p. 367), a Constituição brasileira incorporou, ao menos sob a perspectiva normativa, a representação dual dos trabalhadores: sindical e extrasindical (também chamada de unitária ou eleita).

A partir desse corte conceitual e didático, serão apresentadas as principais estruturas de representação interna dos trabalhadores surgidas no Brasil. Antes, algumas ressalvas.

Embora se possa falar do "local de trabalho" como um elemento geral, verificável para o conjunto das empresas e dos trabalhadores, sabe-se que cada local de trabalho é singular, apresentando características próprias a depender dos sujeitos que ali atuam, da atividade produtiva, do ambiente organizacional e cultural, dentre outros fatores. Dessa forma, 
na relação entre os elementos geral e local deve-se sempre ter em vista a presença da similitude e da especificidade, e as contradições surgidas dessa interação.

Com a RLT ocorre o mesmo e, talvez, de forma mais intensa, o que levou Waldemar Santos Pedreira Filho a afirmar a dificuldade, ou mesmo a impossibilidade, de se falar em uma teoria geral das organizações no local de trabalho (1998, p. 2).

Tendo em vista essa observação e os objetivos do presente artigo, tratar-se-ão, os próximos passos, da tentativa de apresentação de uma síntese dos elementos mais gerais observados em determinadas formas de RLT, sem a pretensão de contemplar todas as experiências.

\subsection{Representação sindical}

A representação sindical em nível de empresa é exercida pelas delegacias ou seções sindicais e pelos delegados sindicais, cuja previsão está na Consolidação das Leis do Trabalho (CLT), nos artigos 517 e 523:

\footnotetext{
Art. 517. Os sindicatos poderão ser distritais, municipais, intermunicipais, estaduais e interestaduais. Excepcionalmente, e atendendo às peculiaridades de determinadas categorias ou profissões, o ministro do Trabalho, Indústria e Comércio poderá autorizar o reconhecimento de sindicatos nacionais.

(...)

$\S 2^{\circ}$ Dentro da base territorial que lhe for determinada é facultado ao sindicato instituir delegacias ou secções para melhor proteção dos associados e da categoria econômica ou profissional ou profissão liberal representada.
}

Art. 523. Os Delegados Sindicais destinados à direção das delegacias ou seções instituídas na forma estabelecida no $\S 2^{\circ}$ do art. 517 serão designados pela diretoria dentre os associados radicados no território da correspondente delegacia. (BRASIL, 1942).

Tratam-se das estruturas de contato entre os trabalhadores de determinado local de trabalho e a direção do sindicato, bem como de intermediação entre os sindicalizados e a empresa no que tange a assuntos laborais e de interesse daqueles.

O delegado sindical é a figura singular de representação sindical interna; a delegacia ou seção sindical, a figura colegiada. As atribuições desses representantes são definidas pelo regramento interno das entidades sindicais.

A atuação dos dirigentes sindicais encontra tutela específica no artigo 543, da CLT, o qual prescreve ser devida a estabilidade provisória ao empregado eleito ( $3^{\circ}$ ), bem como garantida a inamovibilidade (caput). 
O Tribunal Superior do Trabalho (TST) entende que essas garantias não alcançam os delegados sindicais, vez que são designados pelo sindicato para a função (art. 523). Não sendo submetidos a processo eletivo, não se enquadram aos exatos termos do $\S 4^{\circ}$, do artigo 543 , da CLT. Tal entendimento está expresso na Orientação Jurisprudencial no 369, da Seção de Dissídios Individuais I do Tribunal (BRASIL, 2008).

Na visão de Marcus Kaufmann, essa interpretação, deveras restritiva, só pode ser admitida para os delegados efetivamente designados pela diretoria sindical, não havendo óbices para que o delegado sindical seja escolhido pelos integrantes da categoria, fato capaz de estender-lhe o foro sindical amplo previsto no artigo 543, da CLT (2005, p. 452).

Ademais, mesmo no caso dos delegados indicados pelo sindicato, é preciso realizar a interpretação da legislação nacional à luz dos princípios e garantias relacionados à liberdade sindical e consagrados pela OIT, em especial aqueles disciplinados nas Convenções $n^{\circ} 98$ e $n^{\circ}$ 135.

Inegável, portanto, que a ausência da garantia da estabilidade provisória fragiliza a atuação dos delegados sindicais.

Por último, cabe mencionar a recente experiência do Comitê Sindical de Empresa (CSE) implantado pelo Sindicato dos Metalúrgicos do ABC. Trata-se de uma forma de organização que parte do "chão de fábrica”, cujos membros, eleitos pelos associados do sindicato, passam a constituir a Direção Plena do Sindicato dos Metalúrgicos (MEIRELLES, 2008, p. 138), numa clara fusão da representação sindical com o sindicato.

\footnotetext{
Entre várias atribuições, cabe ao CSE fiscalizar o cumprimento da legislação e dos instrumentos coletivos, encaminhar reivindicações dos trabalhadores e negociar condições específicas de trabalho na empresa. É ele também que se encarrega de negociar a adequação da aplicação da legislação trabalhista à realidade da empresa e à vontade dos trabalhadores, por meio dos acordos coletivos de trabalho (TRIBUNAL SUPERIOR DO TRABALHO, 2012).
}

\subsection{Representação não sindical}

No Brasil, a representação não sindical remete ao contexto do "novo sindicalismo", apresentando-se como tentativa de melhor tratar de problemas do cotidiano da empresa, relegados a segundo plano pela estrutura oficial (KAUFMANN, 2005, p. 366).

A doutrina visualiza tal representação nas seguintes hipóteses: a) artigo 11 da Constituição da República (representação por via singular); b) organismos sem personalidade jurídica definida, a exemplo das comissões de empresa ou comissões de fábrica e da 
comissão de negociação prevista no artigo $4^{\circ}$, §2 , da Lei ${ }^{0} 7.783$, de 28 de junho de 1989 Lei de Greve; c) artigo $7^{\circ}$, inciso XI, da Constituição da República, ao assegurar aos trabalhadores a participação na gestão, excepcionalmente (KAUFMANN, 2005, p. 374).

Geralmente, a representação unitária concretiza-se por meio da figura do representante de pessoal (individual) ou das comissões de empresa ou comissões de fábrica (figura coletiva).

Em relação à previsão do artigo $7^{\circ}$, inciso XI, da Constituição, e ao debate mais amplo da cogestão, há posições que entendem não se tratar propriamente de RLT, conforme será apresentado ao final.

\subsubsection{Representante de pessoal}

O artigo 11 da Constituição da República Federativa do Brasil assegura, nas empresas de mais de duzentos empregados, a eleição de um representante encarregado da promoção do entendimento direto com os empregadores.

O representante dos empregados ou delegado de pessoal é eleito diretamente pelos trabalhadores e desvinculado dos sindicatos que atuam naquele âmbito, tendo atribuições limitadas às atividades de diálogo com o empregador para a resolução de problemas individuais ou coletivos, dentro dos limites que não configurem a formalização de negociação ou contratação coletivas.

Conforme afirma José Francisco Siqueira Neto, pela primeira vez uma Constituição brasileira trouxe dispositivo específico à representação no local de trabalho (SIQUEIRA NETO, 2001). Tal novidade, porém, resta bastante prejudicada, em razão da não regulamentação, pela legislação infraconstitucional, dos procedimentos e critérios de eleição e das garantias dispensadas a esses representantes.

A primeira questão polêmica diz respeito à possibilidade de eleição de mais de um representante dos empregados, visto que o universo de empresas com mais de duzentos empregados abrange tanto estruturas situadas nesse limite, como grandes grupos empresariais com milhares de funcionários. Parte da doutrina compreende que a Constituição assegura um representante, podendo, entretanto, “concordar o empregador com a existência de mais de um, o que deve ser encarado como ato de liberalidade, frente a uma reivindicação, nesse sentido, dos trabalhadores” (BRITO FILHO, 2012, p. 318). 
A doutrina divide-se, ainda, quanto ao âmbito da representação: se por empresa ou por estabelecimento. Enquanto José Francisco Siqueira Neto entende tratar-se de um representante por empresa (2001, p. 97), há quem afirme que o texto constitucional deve ser interpretado de modo a possibilitar representantes por estabelecimento, já que, em empresas com várias unidades, é difícil para um só representante acompanhar as situações cotidianas de ambientes de trabalho situados em cidades ou estados diferentes (BRITO FILHO, 2012, p. 318).

A legislação não assegurou, também, estabilidade ao representante dos empregados, vez que o artigo 11 mencionado é omisso sobre o tema e o artigo $8^{\circ}$, VIII, da Constituição, refere-se tão somente a dirigentes e representantes sindicais. Tal fato é um dos principais entraves à consolidação da previsão constitucional, pois, conforme sabido, a não instituição de garantias tolhe a liberdade do representante, enfraquecendo, em último plano, a representação dos trabalhadores no local de trabalho.

É digno de registro o Precedente Normativo $n^{0}$ 86, da Seção Especializada em Dissídios Coletivos, do TST, transcrito abaixo:

REPRESENTANTES DOS TRABALHADORES. ESTABILIDADE NO EMPREGO (positivo). Nas empresas com mais de 200 empregados é assegurada a eleição direta de um representante, com as garantias do art. 543, e seus parágrafos, da CLT (BRASIL, 1992).

Essa orientação constitui importante elemento de unificação do entendimento do TST sobre a matéria e vai ao encontro das disposições da Convenção ${ }^{0}$ 135, da OIT, cujo artigo $1^{\circ}$ estabelece que os representantes dos trabalhadores na empresa devem ser beneficiados com uma proteção eficiente contra quaisquer medidas que possam vir a prejudicá-los.

Também o Ministério Público do Trabalho (MPT) expediu a Recomendação n ${ }^{0}$ 1, de 15 de agosto de 2011, com orientações destinadas a empregadores e a sindicatos das categorias profissional e econômica, no sentido de respeitarem e estimularem a instituição de representação dos empregados no âmbito da empresa.

Quanto aos sindicatos das categorias profissionais, especificamente, o MPT recomenda, além de postura proativa para negociar disposições e garantias aos representantes dos empregados:

ORGANIZAR a eleição para escolha do representante dos trabalhadores e suplentes, salvo na hipótese em que os próprios trabalhadores tomem tal iniciativa ou em que haja conflito entre dois ou mais sindicatos legitimados interessados na condução 20 das eleições na empresa, caso em que o Ministério Público do Trabalho se dispõe 
a mediar o impasse ou determinar providencias para a realização do pleito (2011, p. 03).

A ausência de regramento satisfatório dessa modalidade de representação não sindical pode explicar porque raríssimos foram os representantes de pessoal eleitos desde a promulgação da Constituição (SIQUEIRA NETO, 2001, p. 97; MARTINS, 2008, p. 748).

\subsubsection{Comissão de empresa ou comissão de fábrica}

José Cláudio Monteiro de Brito Filho conceitua a comissão de empresa - ou comissão de fábrica - como “órgão colegiado de representação direta de todos os trabalhadores, composta por membros escolhidos por eles, com exercício no interior da empresa, e tendo como atribuição a coordenação e defesa dos interesses perante o empregador” (2012, p. 336). O citado autor observa que é a forma representativa que mais vem adquirindo espaço nos locais de trabalho (BRITO FILHO, 2012, p. 324).

Alguns dos elementos da comissão de empresa podem ser encontrados na concepção dos Conselhos de Fábrica, de Antônio Gramsci, expressa nos escritos do Ordine Nouvo. Para Gramsci, essa forma organizativa constituiria a menor célula do poder operário e, portanto, a base da organização dos trabalhadores, diferentemente dos sindicatos e dos partidos, que não aglutinariam todos aqueles que laboram (BRITO FILHO, 2012, p. 324).

No Brasil, em que pese o reconhecimento da existência de experiências de comissões de empresa desde as primeiras décadas do século XX (BRITO FILHO, 2012, p. 329), é o “novo sindicalismo” da década de 1970 o marco da emergência das comissões, especialmente em decorrência das greves iniciadas em 1978 na Scania e na Ford, ambas em São Bernardo do Campo (MEIRELLES, 2008, p. 133).

\footnotetext{
Foi, realmente, na Ford, após o nascimento desse "novo sindicalismo", que se institucionalizou uma forma de representação interna organizada, com estatuto próprio, com regras de atuação, com delimitação de matérias para a negociação coletiva, com garantia de emprego, com processo eleitoral interno (participando todos os trabalhadores da empresa, associados ou não do sindicato) e, sobretudo, com reconhecimento da representatividade por parte da empresa (MEIRELLES, 2008, p. 135).
}

Isso num contexto em que as reivindicações trabalhistas voltaram-se, primordialmente, para o local de trabalho, segundo observação de Iram Jácome Rodrigues (apud BRITO FILHO, 2012, p. 329). 
A multiplicação das experiências das comissões de fábrica mostrou estruturas organizativas bastante diversificadas. Enquanto a comissão implementada na Ford possuía natureza híbrida - representava os interesses de todos os trabalhadores da empresa, os quais participavam do processo de escolha dos representantes, mas a coordenação da comissão estava a cargo de diretores de base do Sindicato dos Metalúrgicos de São Bernardo do Campo e Diadema - a comissão dos trabalhadores da Volkswagen já nasceu desvinculada organicamente do sindicato (MEIRELLES, 2008, p. 136).

No Brasil, as Comissões de Empresa constituem órgãos sem personalidade jurídica (BRITO FILHO, 2012, p. 337) e encontram seu fundamento normativo no direito de associação que todo ser humano possui, reconhecido expressamente pela Constituição brasileira (art. $5^{\circ}$, inciso XVII; art. $8^{\circ}$, caput).

Como não há previsão legal, para constituírem-se como interlocutoras legítimas no local de trabalho, as comissões precisam ser objeto de negociação com os empregadores, materializada em convenção ou acordo coletivo de trabalho. Ou, ao menos, serem reconhecidas pelo empregador depois de formadas espontânea e diretamente pelos trabalhadores.

Historicamente, essas comissões foram constituídas em grandes empresas, especialmente do setor industrial, onde há a concentração de centenas de trabalhadores num mesmo local de trabalho. Nada impede, porém, sua constituição em empresas de pequeno e médio porte.

\subsubsection{Considerações sobre a Comissão Interna de Prevenção de Acidentes e outras comissões com participação de trabalhadores}

A Comissão Interna de Prevenção de Acidentes (CIPA) é prevista, pela CLT, como um dos órgãos de Segurança e Medicina do Trabalho nas empresas, sendo formada, paritariamente, por representantes dos trabalhadores e do empregador, a partir da combinação do grau de risco do estabelecimento com o número de empregados (BRITO FILHO, 2012, p. 318).

Como se percebe, trata-se de uma forma representativa restrita, afeta à matéria específica. Fato que, aliado à sua composição paritária, leva alguns autores a afirmarem não se tratar de típica figura de RLT (KAUFMANN, 2005; MEIRELLES, 2008, p. 132). 
A mesma crítica é dirigida às representações de trabalhadores nas comissões de conciliação prévia (art. 625-B, da CLT), nas comissões mistas de consulta e colaboração no plano da empresa e sobre participação nos lucros (art. 621, da CLT) e nas comissões temáticas e/ou transitórias em geral (KAUFMANN, 2005, p. 453-457).

Outros autores, porém, entendem que a CIPA é uma modalidade de RLT (BRITO FILHO, 2012, p. 317).

\subsubsection{Considerações sobre a participação dos trabalhadores na gestão da empresa}

$\mathrm{O}$ artigo $7^{\circ}$, inciso XI, da Constituição brasileira assegura a participação dos trabalhadores na gestão da empresa, em caráter excepcional, conforme definido em lei.

A doutrina aponta a existência de previsão similar já na Constituição de 1967, no art. 158, inciso V (MARTINS, 2008, p. 749).

A participação na gestão ou cogestão é definida por Antônio Álvares da Silva como a participação verificada na empresa que envolve a vontade do empregado ou do empregador, através de representação apropriada (SILVA, 1991, p. 27).

O prefixo co, que entra na formação da palavra "co-gestão", designa exatamente que se trata de decisão que não se toma isoladamente mas com a participação de outra vontade. Não se trata mais de decisão que o empregador ou o empregado isoladamente tomariam (SILVA, 1991, p. 27).

É objetivo da cogestão a institucionalização da participação e da forma cooperativa no âmbito da empresa (SILVA, 1991, p. 44), visando a uma efetiva integração entre o trabalho e o capital (SILVA, 1991, p. 45).

Pode dar-se por empresa ou por estabelecimento, mediante lei ou norma coletiva.

A cogestão é uma forma de participação bastante aperfeiçoada na Alemanha (MARTINS, 2008, p. 750), mas pouco conhecida e praticada no Brasil.

Antônio Álvares da Silva visualiza em algumas estruturas de representação interna apresentadas acima típicas manifestações da cogestão no estabelecimento, como os delegados de pessoal e os delegados sindicais (1991, p. 192). Todavia, outros autores afirmam que as tradicionais estruturas de RLT não se confundem com a cogestão, tendo em vista a disciplina constitucional do instituto e a realidade das estruturas de representação no Brasil (SIQUEIRA NETO, 2001). 
O exame das espécies de RLT a partir da mencionada concepção da cogestão, entretanto, ultrapassa os objetivos previstos para este artigo.

\section{A REPRESENTAÇÃO NO LOCAL DE TRABALHO NA ITÁLIA}

A representação dos trabalhadores no local de trabalho, na Itália, tem origem nas comissões internas, no início do século XX. Surgidas com a greve geral de 1904 (BRITO FILHO, 2012, p. 327), foram regulamentadas, pela primeira vez, em 1906 (BARROS, 1998, p. 186), a partir do acordo entre a Federação Italiana Operária Metalúrgica e a fábrica de automóveis Itala, de Turim (MARTINS, 2008, p. 742). Outros reconhecimentos ocorreram, posteriormente, nas empresas Borsalino, em 1908, e Fiat, em 1912 (CENTRAL ÚNICA DOS TRABALHADORES; CONFEDERAZIONE GENERALE ITALIANA DEL LAVORO, 2009, p. 20).

Conforme afirma Alice Monteiro de Barros, de 1919 a 1922, as comissões internas desenvolveram-se paralelamente ao modelo dos conselhos de fábrica (1998, p. 186). Estes possuíam inspiração nitidamente revolucionária, ancorados na doutrina e na prática política do grupo do Ordine Nuovo, do qual fazia parte Antônio Gramsci (BRITO FILHO, 2012, p. 326).

Com o advento do regime fascista, tais organismos foram extintos e foi criada a figura do confidente de empresa, única forma de representação do trabalhador naquele âmbito (BARROS, 1998, p. 186).

Após a queda do fascismo, as comissões internas ressurgiram dotadas da prerrogativa de contratação coletiva no âmbito da empresa. Todavia, as comissões foram sofrendo restrições ao longo dos anos até serem substituídas por outras formas associativas nos locais de trabalho, em especial pelas seções sindicais de empresa (BARROS, 1998, p. 186).

As seções sindicais não constituíam órgãos unitários e obrigatórios; tratavam-se de órgãos de representação voluntária, próprio dos sindicatos, tendo sido difundidas em poucas empresas de categorias mais sindicalizadas (BARROS, p. 186).

O final da década de 1960 inaugura um novo momento da representação no local de trabalho na Itália, a partir do surgimento de novas formas de representação direta dos trabalhadores, a saber, os delegados, a assembléia e o conselho de fábrica ou de delegados (BRITO FILHO, 2012, p. 327). 
Essas novas estruturas originaram-se do anseio da base operária por participação e caracterizaram-se pela representação independentemente de filiação sindical (BRITO FILHO, 2012, p. 327).

Um marco na disciplina das relações trabalhistas e da RLT na Itália é a Lei $n^{\circ}$ 300, de 20 de maio de 1970, o Statuto dei Lavoratori, o qual, em seu artigo 19, possibilita a constituição de representação sindical nas empresas (cuja sigla, em italiano, é RSA), por iniciativa dos trabalhadores:

\section{Art. 19}

Estabelecimento de representação sindical na empresa

Representação sindical na empresa pode ser criada por iniciativa dos trabalhadores em cada unidade produtiva, dentro de:

a. [...];

b. associações sindicais que sejam signatárias das convenções coletivas de trabalho aplicados na unidade produtiva

No âmbito das empresas com várias unidades produtivas, os sindicatos podem estabelecer órgãos de coordenação (ITALIA, 2012b). ${ }^{2}$

O ordenamento jurídico italiano apresenta um sistema de representação dos trabalhadores fortemente ligado aos sindicatos, o que resta demonstrado pela localização dos artigos que tratam da representação interna: no capítulo referente à atividade sindical do Estatuto dos Trabalhadores (OLIVEIRA NETO, 2012, p. 01).

A Itália também é signatária da Convenção ${ }^{0}$ 135, da OIT, havendo, portanto, a convivência entre representações sindicais e não sindicais no país.

Conforme indicação da doutrina italiana, reproduzida por Marcus Kaufmann, há uma representação coletiva complexa na empresa:

[...] Formada por um sujeito de base eletiva, que seria a representação unitária (rappresentanza unitaria), e por um sujeito de base associativa, que seria o sindicato (organizzazione sindacale territoriale di categoria). Para aquela primeira representação, as atividades desenvolvidas envolveriam as de caráter informativo e consultivo, de participação técnica, econômica ou social, exemplificadas no Decreto Legislativo $n^{\circ} 626$ de 1994 (2005, p. 422).

Há, ainda, as comissões internas (commissione interne), de natureza não sindical, que desenvolvem as seguintes funções na empresa: a) prevenção e controle da aplicação dos

\footnotetext{
${ }^{2}$ Art. 19 - Constituzione delle rappresentanze sindacali aziendali

Rappresentanze sindacali aziendali possono essere costituite ad iniziativa dei lavoratori in ogni unità produttiva, nell'ambito:

a. $[\ldots]$;

b. delle associazioni sindacali che siano firmatarie di contratti collettivi di lavoro applicati nell'unità produttiva. Nell'ambito di aziende con più unità produttive le rappresentanze sindacali possono istituire organi $2 \bar{\not}$ coordinamento. (ITÁLIA, 2012b)
} 
contratos coletivos de trabalho; b) consulta quanto à época das férias, turnos de trabalho, intervalos intrajornada; c) proposição de métodos de trabalho e de serviços da empresa; d) gestão das atividades sociais, recreativas, culturais, etc. (KAUFMANN, 2005, p. 422). Ressalta-se que a comissão interna não possui poder de contratação coletiva (KAUFMANN, 2005, p. 423).

Por meio do Acordo Interconfederal assinado pelas confederações sindicais italianas - CGIL $^{3}$, CISL $^{4}$ e UIL ${ }^{5}$ - e pela Confindustria ${ }^{6}$ e Intersind ${ }^{7}$, em $1^{0}$ de dezembro de 1993, surgiram as Representações Sindicais Unitárias (RSU), “uma simbiose de representação sindical no local de trabalho e representação unitária nas empresas com pelo menos 15 (quinze) empregados” (KAUFMANN, 2005, p. 423).

Tal Acordo modificou o sistema de representação interna previsto no artigo 19 do Estatuto dos Trabalhadores (KAUFMANN, 2005, p. 423), vez que:

[...] Reconhece que a representação dos trabalhadores no âmbito da empresa, quando sindical, deverá ser “unitária” no sentido de que deverá congregar, em seu interior, os diversos sindicatos existentes em atuação na empresa. A RSU e o órgão sindical correspondente ao território de atuação da RSU, signatário do contrato coletivo nacional de trabalho, podem formalizar contratação coletiva com os procedimentos, modalidades e nos limites estabelecido pelo contrato coletivo nacional aplicável à unidade produtiva (KAUFMANN, 2005, p. 423).

O Estatuto dos Trabalhadores traz, também, prerrogativas e garantias para o exercício da representação, dentre as quais se destaca: a) a exigência de que a transferência de unidade de representante sindical, candidato e membro de comissão interna seja precedida de autorização (nulla osta) do sindicato (art. 22); b) a concessão de licenças, remuneradas ou não, para os componentes da RSA (arts. 23 e 24); c) em unidades com mais de 200 funcionários, a RSA faz jus a um local para o exercício de suas funções dentro da empresa ou em suas imediações; as unidades com menos funcionários tem direito de usar, se assim o solicitarem, um local adequado para suas reuniões (art. 27); d) poder de convocar assembléia de trabalhadores, os quais poderão reunir-se na unidade de produção, fora do expediente e durante a jornada de trabalho, observado o limite de 10 (dez) horas por ano, para o qual será pago o salário normalmente (art. 20) e de realizar referendo sobre assuntos de interesse na

3 Confederação Geral Italiana de Trabalhadores, fundada em 1944, sob influência dos comunistas, dos socialistas e dos democrata-cristãos (MEIRELLES, 2008, p. 129).

${ }^{4}$ Confederação Italiana de Sindicatos de Trabalhadores, surgida no fim da década de 1940, ligada à Democracia Cristã e à Ação Católica dos Trabalhadores Italianos (ACLI). (MEIRELLES, 2008, p. 129).

5 União Italiana dos Trabalhadores, também originária do final da década de 40, com orientação dos republicanos social-democratas e socialistas (MEIRELLES, 2008, p. 129).

${ }^{6}$ Confederação Geral da Indústria Italiana.

${ }^{7}$ Organização que representa empresas públicas. 
empresa (art. 21); e) utilização de espaço para informação e comunicações sobre assuntos de interesse sindical e trabalhista (art. 25) (MARTINO, 2012, p. 03-04).

O artigo 46 da Constituição italiana, de 1948, assegura aos trabalhadores o direito de participar da gestão da empresa:

Art. 46. Com a finalidade de elevação econômica e social do trabalho em harmonia com as necessidades da produção, a República reconhece o direito dos trabalhadores de colaborarem, nas formas e dentro dos limites estabelecidos por lei, na gestão das empresas (ITÁLIA, 2012a). ${ }^{8}$

Por fim, imperioso mencionar a Diretiva nº 94/45, do Conselho da União Européia, de 22 de setembro de 1994, que, com vistas a melhorar o direito à informação e consulta dos trabalhadores nas empresas ou grupos de empresas de dimensão comunitária, instituiu a figura dos Conselhos de Empresa Europeus (CEEs). Conforme Amauri Mascaro do Nascimento, esse organismo dá-se:

[...] Nas empresas com mais de 1.000 empregados nos Estados-membros e pelo menos em dois deles, com 150 ou mais empregados; em grupos de empresas com mais de 1.000 trabalhadores ou mais nos Estados-membros e que tenham, ao menos, duas empresas em dois desses, com 150 ou mais empregados (NASCIMENTO, 2005, p. 280).

Trata-se de importante instrumento jurídico de organização dos trabalhadores em tempos de globalização, ao fazer corresponder à crescente operação das empresas em escala transnacional mecanismos de representação e participação dos trabalhadores adequados a essa escala.

\section{CONSIDERAÇÕES FINAIS}

A organização dos trabalhadores no local de trabalho é fruto de conquistas históricas da classe trabalhadora em seu conjunto. Surgida nos países europeus de capitalismo avançado, estendeu-se aos demais países, paralelamente, à expansão da grande indústria.

Influenciou e sofreu as influências da evolução do conceito de liberdade sindical, que, hoje, abarca uma diversidade de experiências e formas de representação dos trabalhadores para a defesa de seus direitos e interesses.

\footnotetext{
${ }^{8}$ Art. 46. Ai fini della elevazione economica e sociale del lavoro in armonia con le esigenze della produzione, la Repubblica riconosce Il diritto dei lavoratori a collaborare, nei modi e nei limiti stabiliti dalle leggi, alla gestione delle aziende (ITALIA, 2012a).
} 
Do exposto, parece claro que a representação dos trabalhadores nos locais de trabalho, a despeito dos avanços práticos e institucionais verificados, ainda se apresenta como desafio para o conjunto dos trabalhadores, tanto na Itália, como no Brasil.

Verifica-se que a Itália possui uma experiência de longa data de RLT, bem como uma legislação básica consentânea com as normas e diretrizes da Organização Internacional do Trabalho. Muitas medidas previstas na Recomendação $\mathrm{n}^{0}$ 143, da OIT, encontram tratamento similar no Estatuto dos Trabalhadores, como é o caso dos parágrafos 10 a 17 da Recomendação e dos artigos 20 a 27 do Estatuto.

O Brasil não possui um regramento nacional amplo para as representações internas dos trabalhadores. O que há são algumas hipóteses previstas na Constituição (art. 7º, XI e art. 11, da CR/88) e na legislação ordinária, especialmente na CLT.

Estruturas importantes de RLT não encontram nenhuma previsão legal, derivando da instituição de cláusulas em negociações coletivas. Essa é a situação das Comissões de Empresa.

É certo que a ausência de legislação não impede a criação e consolidação de instrumentos de RLT, os quais podem partir da iniciativa das partes e da autonomia coletiva, para citar, novamente, as Comissões de Empresa brasileiras. Entretanto, é preciso considerar que a inexistência de mecanismos legais mínimos dificulta a RLT no caso de pequenas empresas e de categorias com menor poder de pressão.

Ademais, mesmo no universo das RLT instituídas por negociação coletiva, há grande disparidade em relação às garantias e às prerrogativas conferidas aos representantes, incluídas negociações em que essa temática fica de fora da pauta ou não é objeto de acordo entre as partes. Fato que, na prática, dificulta a atuação das RLT.

Em relação à coexistência de representações sindicais e não sindicais nas empresas, é produtivo que se adote uma postura colaborativa. O que, por certo, não é tarefa fácil, diante dos eventuais conflitos de atribuições, de práticas e de composição político-ideológica. Além disso, não é incomum que as representações não sindicais sejam criadas ou utilizadas pelos governos e empresários como forma de enfraquecer o poder sindical; tampouco é incomum a existência de sindicatos burocratizados e distanciados dos interesses e dos problemas imediatos da base dos trabalhadores.

Entende-se, aqui, que os riscos de conflitos são inerentes ao processo de constituição das representações, mas podem ser minimizados se buscadas fórmulas de convivência 
adequadas ao objetivo final dos organismos: coordenar e defender os interesses dos trabalhadores.

Nesses tempos de flexibilização e precarização do trabalho, assiste-se à hipertrofia do poder do capital em nível mundial, o que se reflete no interior das empresas e nas relações trabalhistas.

Tal fato, aliado às dificuldades de mobilização e de criação de identidade de que padecem os sindicatos, indicam a necessidade de se repensar a própria dinâmica do movimento sindical e o papel que se tem conferido à organização no local de trabalho. 


\section{REFERÊNCIAS BIBLIOGRÁFICAS}

ANTUNES, Ricardo. Os sentidos do trabalho: ensaio sobre a afirmação e a negação do trabalho. 2. ed. São Paulo: Boitempo, 2009.

BARROS, Alice Monteiro de. Representante dos empregados no local de trabalho. Revista do Tribunal Regional do Trabalho da $3^{\text {a }}$ Região. Belo Horizonte: ano 28, n. 58, janeiro/dezembro, 1998, p. 179-188.

BRASIL. Consolidação das Leis do Trabalho. Decreto-lei n. 5.452, de 01 de maio de 1942. Aprova a Consolidação das Leis do Trabalho. Diário Oficial da União, Rio de Janeiro, 04 de setembro de 1942.

Tribunal Superior do Trabalho. Seção de Dissídios Individuais I. Orientação Jurisprudencial no 369. Estabilidade provisória. Delegado sindical. Inaplicável. Diário Eletrônico da Justiça do Trabalho, 03 dez. 2008.

Tribunal Superior do Trabalho. Seção Especializada em Dissídios Coletivos. Precedente Normativo $n^{\circ}$ 86. Representantes dos trabalhadores. Estabilidade no emprego (positivo). Diário da Justiça, 08 set. 1992.

BRITO FILHO, José Cláudio Monteiro de. Direito Sindical: análise do modelo brasileiro de relações coletivas de trabalho à luz do Direito Comparado e da Doutrina da OIT - Proposta de inserção da Comissão de Empresa. 4. ed. São Paulo: LTr, 2012.

CASAGRANDE, Cássio. A reforma sindical e a representação dos trabalhadores no local de trabalho e na justiça. Disponível em: <http://www.soc.puc-

rio.br/cedes/PDF/cidadaniatrabalho/reforma\%20sindical.pdf>. Acesso em 20 fev. 2012.

CENTRAL ÚNICA DOS TRABALHADORES (CUT); CONFEDERAZIONE GENERALE ITALIANA DEL LAVORO (CGIL). Organização sindical: avançar rumo à liberdade, autonomia e organização no local de trabalho. São Paulo: CUT, 2009. Disponível em: $<$ http://www2.cut.org.br/index2.php?option=com_docman\&task=doc_view\&gid=1062\&Item id=243>. Acesso em: 05 fev. 2012.

ITALIA. Costituzione della Repubblica Italiana. Disponível em:

<http://www.comune.fi.it/costituzione/italiano.pdf>. Acesso em: 10 abr. 2012a. 
Legge 20 maggio 1970, n. 300 (Statuto dei lavoratori). Disponível em:

<http://www.lavoro.gov.it/NR/rdonlyres/77A26F68-C12E-4671-A260-

2D469405622E/0/19700520_L_300.pdf>. Acesso em: 10 abr. 2012b.

KAUFMANN, Marcus de Oliveira. Das práticas anti-sindicais às práticas antirepresentativas: sistemas de combate e a tutela de representações coletivas de trabalhadores. São Paulo: LTr, 2005.

MARTINO, Enzo. Rappresentanze Sindacali (RSA - RSU). Disponível em: $<$ http://www.wikilabour.it/(S(cfedyauf2gubsz452tyykdug))/Print.aspx?Page=Rappresentanze \%20Sindacali\&AspxAutoDetectCookieSupport=1>. Acesso em: 28 mar. 2012.

MARTINS, Sérgio Pinto. Direito do Trabalho. 24. ed. São Paulo: Atlas, 2008.

MEIRELLES, Davi Furtado. Negociação coletiva no local de trabalho: a experiência dos metalúrgicos do ABC. São Paulo: LTr, 2008.

MINISTÉRIO PÚBLICO DO TRABALHO. Notificação Recomendatória n⿳0 01, de 15 de agosto de 2011. Disponível em:

<http://www.prt22.mpt.gov.br/publicacoes/NR_01_2011_Conalis.pdf>. Acesso em: 03 dez. 2011.

NASCIMENTO, Amauri Mascaro. Compêndio de Direito Sindical. 4. ed. São Paulo: LTr, 2005.

OLIVEIRA NETO, Alberto Emiliano de. Representação dos trabalhadores nas empresas. Jus Navigandi, Teresina, ano 16, n. 3015, 3 out. 2011 . Disponível

em: <http://jus.com.br/revista/texto/20114>. Acesso em: 2 maio 2012.

ORGANIZAÇÃO INTERNACIONAL DO TRABALHO (OIT). Convenção no 135.

Proteção de Representantes de Trabalhadores. Aprovada na 56 reunião da Conferência

Internacional do Trabalho. Genebra, 1971a. Disponível em:

<http://www.oit.org.br/node/489>. Acesso em 10 abr. 2012.

Recomendação $\mathbf{n}^{\circ} \mathbf{1 4 3}$. Sobre proteção e facilidades a serem dispensadas a representantes de trabalhadores na empresa. Genebra, 1971b. Disponível em: <http://www.oitbrasil.org.br/content/sobre-prote\%C3\%A7\%C3\%A3o-e-facilidades-seremdispensadas-representantes-de-trabalhadores-na-empresa>. Acesso em 10 abr. 2012. 
PEDREIRA FILHO, Waldemar Santos. Comissões de Fábrica: um claro enigma. Cad. Est. Soc. Recife. v. 14,n. 1, p. 117146, jan-jun., 1998. Disponível em:

<http://periodicos.fundaj.gov.br/index.php/CES/article/viewArticle/467>. Acesso em: 20 abr. 2012.

RAGHI, Luiz Vagner; MARRAS, Jean Pierre. A representação no local de trabalho: uma análise contemporânea do ABC paulista. Disponível em:

$<$ http://sare.unianhanguera.edu.br/index.php/anudo/article/viewArticle/457>. Acesso em 30 abr. 2012.

SILVA, Antônio Álvares da. Co-gestão no estabelecimento e na empresa. São Paulo: LTr, 1991.

SILVA, Claudio Santos da. Liberdade Sindical no Direito Internacional do Trabalho. São Paulo: LTr, 2011.

SINDICATO DOS EMPREGADOS DE TECNOLOGIAS DA INFORMAÇÃO NOS ESTADOS DO AMAPÁ E DO PARÁ; PROCESSAMENTO DE DADOS DO ESTADO DO PARÁ. Acordo Coletivo de Trabalho 2010/2012. Disponível em:

<http://www3.mte.gov.br/sistemas/mediador/>. Acesso em 03 mai. 2012.

SIQUEIRA NETO, José Francisco. Liberdade sindical e representação dos trabalhadores nos locais de trabalho no Brasil: obstáculos e desafios. In: PEREIRA, Armand F. (org. e ed.). Reforma sindical e negociação coletiva. Brasília: Organização Internacional do Trabalho, 2001, pp. 81-105.

TRIBUNAL SUPERIOR DO TRABALHO. Experiência de metalúrgicos do ABC será discutida no Seminário sobre Liberdade Sindical do TST. Disponível em:

<http://www.tst.gov.br/web/guest/noticias/-/asset_publisher/89Dk/content/id/1394937>. Acesso em: 28 mar. 2012. 